\title{
GERI ÇEKME YÖNTEMI VE KULLANIMINI ETKILEYEN FAKTÖRLER
}

\section{WITHDRAWAL METHOD AND THE AFFECTING FACTORS OF ITS USE}

\author{
Rukiye TÜRK ${ }^{1}$ \\ Füsun TERZioĞLU ${ }^{2}$
}

\section{ÖZET}

Geri çekme yöntemi birçok toplumda çiftler tarafından doğurganlığı kontrol etmek için kullanılan ve bilinen en eski geleneksel aile planlaması yöntemidir. Romanya, Bulgaristan, Ermenistan gibi pek çok ülkede ve Türkiye'de yaygın olarak kullanılmaktadır. Geri çekme yönteminin kullanımı, istenmeyen gebeliklere neden olmasına rağmen, hala en çok tercih edilen geleneksel aile planlaması yöntemlerinden birisidir. Geri çekme yönteminin kullanımını; sosyo-ekonomik durum ve eğitim düzeyi, erkeklerin aile planlaması kullanımına olan destek veya engelleri, maliyetinin olmaması ve her durumda erişilebilir olması, yöntem kullanımının dini açıdan bir sakınca olmaması gibi özellikler ve düşünceler etkilemektedir. Son yıllarda, kadınlara yönelik olan modern yöntem kullanımının daha çok teşvik edilmesine rağmen geri çekme yönteminin çiftler tarafından ısrarlı bir şekilde kullanılmaya devam edildiği görülmektedir. Bu nedenle de geri çekme yöntemi aile planlaması programlarına entegre edilmelidir. Bunun yanısıra, geri çekme yönteminin kullanımını etkileyen faktörlerin bilinmesi yönteme ilişkin sağlık personelleri tarafından verilecek olan eğitim ve danışmanlık hizmetlerinin etkin olmasını sağlayacaktır. Böylece toplum sağlığının yükseltilmesine katkıda bulunacağı düşünülmektedir.

Anahtar Kelimeler: Geri çekme yöntemi, geleneksel yöntem, tutum, aile planlaması.

\section{ABSTRACT}

The withdrawal method is used by couples in many societies to control fertility and it's the oldest known traditional family planning method. It has been used widely in many countries such as Romania, Bulgaria, and Armenia as well as in Turkey. The use of withdrawal method, despite the fact that it can cause unwanted pregnancies, is still one of the most

\footnotetext{
${ }^{1}$ Dr, Kafkas Üniversitesi Kars Sağlık Yüksekokulu, rahsantur@gmail.com

${ }^{2}$ Prof. Dr., Hacettepe Üniversitesi, Hemşirelik Fakültesi, fusun@hacettepe.edu.tr
} 
preferred traditional family planning methods. Notwithstanding, the use of the withdrawal method is effected by aspects and thoughts such as the socio-economic state and level of education, men's support or obstruction in using family planning, having no cost and being reachable in any circumstances, being favorable from the religious perspective. In recent years, it's been noticed that the withdrawal method has been continuously used with persistence by couples despite the encouragement for women to use modern methods. For this reason the withdrawal method should be integrated in family planning programs. Notwithstanding, it's been thought that to know the factors effecting withdrawal method usage can ensure efficiency of the training and consultancy services given by method related health professionals and contribute to an increase in public health.

Key words: The withdrawal method, traditional methods, attitude, family planning.

\section{GíRiş}

\section{Geri Çekme Yönteminin Tarihçesi ve Tanımı}

Geri çekme yöntemi birçok toplumda çiftler tarafından doğurganlığı kontrol etmek için kullanılan ve bilinen en eski aile planlaması yöntemlerinden biridir (Anonim, 1984; Rogow ve Horowitz, 1995; Samtow, 1995). Yazılı olan İslam tarihinde bu yöntemin kullanımına ilişkin tartışmalar $\mathrm{Hz}$. Muhammet dönemine kadar dayanmaktadır (Omran, 1992). Bunun yanı sıra İslam hukukçuları ve doktorları tarafından Arapça yazılan tıbbi ve felsefi metinlerde, o dönemin İslam aleminde geri çekme yönteminin yaygın bir uygulama alanına sahip olduğu belirtilmektedir (Elgood, 1970). Türkiye'de 1960 yılı öncesindeki aile planlaması yöntemlerinin kullanımına ilişkin bilgilerimiz sınırlıdır. Duben ve Behar'in makalesinde (1996), Osmanlı İmparatorluğu'nun son dönemleri ile Cumhuriyet'in ilk dönemlerinde İstanbul ve çevresinde geri çekme ve emzirmenin gebeliği önleyici yöntemler olarak yaygın bir şekilde kullanıldığını açıklanmaktadır (Duben ve Behar, 1996).

Geri çekme yöntemi, halk arasında "çekilme", "dikkatli olma", "dışarı boşalma", "erkeğin korunması" gibi pek çok isim verilmiştir. Geri çekme (Coitus interruptus), ilişki sırasında erkeğin boşalmadan hemen önce penisini vajinadan çıkarıp dışarıya boşalmasıdır (Akın, 1996; Anonim, 2005).

\section{Geri Çekme Yönteminin Kullanım Sıklığı}

Dünya genelinde 15-49 yaş aralığındaki kadınlar arasında geri çekme yönteminin kullanımının, evli kadınlar arasında \%3,1, gelişmiş 
bölgelerde \%6,7 ve az gelişmiş bölgelerde \%2,5 olduğu belirtilmektedir. Geri çekme yönteminin 15-49 yaş evli kadınlar arasında, kullanım sıklığı; Doğu Avrupa ülkelerinde; Bulgaristan (\%19.1) Moldovya (\%19.6), Ukrayna (\%10.3), Güney Avrupa ülkelerinde ise; Arnavutluk (\%60.0), Yunanistan $(28.8)$ İtalya $(18,2)$ ve Karadağ $(\% 40,6)$ olarak belirlenmiştir. Bununla birlikte, geri çekme yönteminin kullanım sıklığı, Batı Asya'da bulunan ülkelerde; Azerbaycan'da \%32.5, Ermenistan'da \%27.7 iken, Bahreyn'de \%26,3 (Anonim, 2011) ve Türkiye'de ise \%26,2'dir (HÜNEE TNSA, 2008). Yapılan çalışmalarda, cinsel yönden aktif olan gençlerin \%59'u (Anonim, 2002), \%48'i (Doğurganlık Bilinci ve Doğal Aile Planlaması, 2005) geri çekme yöntemini kullandığı belirlenmiştir (Anonim, 2002). Geri çekme yönteminin yaygın olarak kullanılmasının nedeni; alternatif yöntemlerin yokluğu ile değil, bireysel tercih ve karar mekanizmaları ile açıklanabileceği belirtilmektedir (Samtow, 1993). 2005)

Geri Çekme Yönteminin Avantajları (Anonim, 1996; Anonim,

- Yöntemin kullanıcılar tarafından güvenilir bulunması,

- Gebelik istendiğinde yöntemin kolay bırakılabilmesi,

- Hormon içermemesi,

- Yan etkisinin olmaması (Yanıkkerem vd. 2006)

- Menstrüal siklusa bağı olmaması,

- Gelecekteki fertiliteyi etkilememesi,

- Diğer aile planlaması yöntemlerinin kullanımına karşı dini inançları olan insanlar için kabul edilebilir bir yöntem olması,

- Kullanımının serbest ve her zaman kullanılabilen bir yöntem olmasıdır (Doğal Aile Planlaması, 1996).

Geri Çekme Yönteminin Belirtilen Dezavantajları (Anonim, 1996; Anonim, 2005; Yanıkkerem vd. 2006; Güven, 2004; Anonim, 1997; Taşkın,2009)

Ejakülasyondan önce vezikula seminalis ve üretrada bulunan bir miktar seminal mayi vajene kaçabilir. Kişilerin otokontrolü koitusa ara vermek için her zaman yeterli olmayabilir.

- Sürekli kullanılığında eşlerde özellikle kadınlarda cinsel doyumsuzluk ve psikolojik gerginliğe yol açabilir. 
- Çiftlerin cinsel tatminini azaltabilir.

- Cinsel yolla bulaşan hastalıkları engellemez.

- Cinsel tecrübesi az olanlarda etkililiğinin daha da az olmasıdır.

- Yöntemin güvenilir olmamasıdır.

Geri Çekme Yönteminin Kullanımının Uygun Olmadığı Durumlar (Anonim, 2005; Anonim, 1997):

- Tıbbi nedenlerle kadının gebe kalmasının sakıncalı olması,

- Sık ve düzenli cinsel ilişkisinin olması Gebelikten sonra belli bir süre ikinci bir gebeliğin istenmemesi,

- Cinsel yolla bulaşan hastalıklardan korunmak istenmesi,

- Eşinin bu yöntemi doğru kullanacağından emin olunmaması; durumunda kullanılması uygun değildir".

\section{Geri Çekme Yöntemi ve İstemsiz Gebelikler}

Dünyada her yıl meydana gelen gebeliklerin yarısı istemsiz/planlanmamış gebeliklerdir. Bu gebeliklerin sayısı yaklaşık 75 milyon civarındadır. İstemsiz gebelikler abortus, ölü doğum ya da canlı doğumla sonuçlanmaktadır (Özalp ve Tanır, 2001). Türkiye'de ise, evli kadınların \%67'si ilerde başka çocuk istemediklerini; yüzde 14'ü ise bir sonraki doğumlarına kadar en az iki yıl beklemek istediklerini belirtmişlerdir. Ülkemizde evlenmiş kadınların \%22'sinin doğurganlık dönemleri boyunca istemli düşük yaptığı belirlenmiştir.Bu kadınların \%39,0'ının son düşükten bir ay önce kullandığı yöntemin geri çekme olduğu belirtilmekte ve düşük sonrası \%32'sinin herhangi bir aile planlaması yöntemi kullanmadığı, \%22,0'ının ise yine geri çekme yöntemini kullanmaya devam ettiği belirlenmiştir (Anonim, 2008). Kitapçıoğlu ve arkadaşlarının çalışmasında kadınların \%31'inin istemli düşük sonrası herhangi bir aile planlaması yöntemi kullanmadığı, \%26'sının ise geri çekme yöntemini kullandığı belirlenmiştir (Kitapçıŏlu ve Yanıkkerem, 2008). Yapılan çalışmalarda kadınların \%38,1'inin istemsiz olarak gebe kalmadan önce en son kullandığı yöntemin geri çekme olduğu belirtilmektedir (Kitapçıoğlu ve Yanıkkerem, 2008; Güngör vd. 2006).

Yapılan bir çalışmada, geleneksel yöntem kullanan kadınların modern yöntem kullanan kadınlara göre daha fazla istemsiz olarak gebe kaldıkları belirtilmektedir. Belçika'da 1971 yılında yapılan bir 
çalışmada geri çekme yöntemini kullanan çiftlerde yaşam boyu gebelik sıklığı \%17 olarak belirlenmiştir (Rogow ve Horowitz, 1995). Kulu-Glasgow ve arkadaşlarının 1988 Türkiye Nüfus ve Sağlık Araştırması bulgularını analiz ettikleri çalışmada geri çekme yöntemini kullanan kadınlarda, gebelik sıklığı \%31,1 olarak belirlenmiştir (Kulu-Glasgow vd. 1991). Yapılan çalışmalarda istemsiz olarak gebe kalan kadınların \%58,7-\%60,6'sının (Yurdakul ve Vural 2001; İnce ve Özyıldırım, 2003) ve \%39'unun geri çekme yöntemini kullandığı belirlenmiştir (Tekiner vd. 2010).

\section{Geri Çekme Yönteminin Tercih Edilme Nedenleri}

Çiftler arasında geri çekme yönteminin kullanımı, gebeliği önleyici diğer yöntemlerle karşılaştırıldığında bu yöntemin maliyetinin olmaması, kimyasallara intiyaç duyulmaması ve her durumda erişilebilir olması ile açıklanabilmektedir. Geri çekme yöntemi erkeklerin otokontrollerine bağlıdır. Geri çekme yönteminin kullanımı herhangi bir sağlık kuruluşuna gitmeyi gerektirmemektedir (Rogow ve Horowitz, 1995). Ayrıca, başka bir yöntemi kullanmayan veya kullanmak istemeyen çiftler içinde pratik bir tercih olabilmektedir (Hatcher vd. 1997).

Yapılan çalışmalar geri çekme yönteminin kullanımının en yüksek olduğu Türkiye, Romanya, Bulgaristan ve Mauritius gibi ülkelerde bu yöntemin kullanılmasının temel nedeninin modern yöntemlerin birtakım yan etkilere neden olacağına ilişkin sağlık endişeleri olduğunu göstermiştir (Finger, 1996; Goldberg ve Toros, 1997; Oodit, 1996). Yapılan diğer çalışmalarda, kadınlar geri çekme yöntemini tercih etme nedenlerini; bu yöntemin eşleri tarafından tercih edilmesini, diğer yöntemlerin başarısızlık hızlarına dair kuşkularının ve bu yöntemden memnuniyetlerini sıralamaktadır (Anonim, 1998; Okun, 1997).

Kullanılan aile planlaması yönteminden bireylerin memnuniyeti yöntem tercihini pozitif yönde etkilemektedir. Geri çekme yönteminin kullanımına ilişkin olarak yapılan bir çalışmada, araştırmaya katılan 1910 kadına geri çekme yönteminden memnuniyetleri sorulduğunda, sadece \% 10'u yöntemden her iki eşin de memnun olduğunu, kadınların \% 75'inin, erkeklerin ise \% 68'inin bu yöntemden memnun oldukları belirlenmiştir (Aytekin vd. 2001). Yanıkkerem ve arkadaşlarının Manisa'da yaptığı çalışmaya göre, geri çekme yönteminden kadınların \%84,4'ü memnun iken, erkeklerde bu sıklık $\% 69,9$ 'dur. Kadınların \%65'inin bu yöntemi kullanırken gebe 
kalmaktan korktuğunu ve \%51'nin ise, istenmeyen gebelikle karşılaştığını ifade etmiştir (Yanıkkerem vd. 2006). Fakat geri çekme yöntemi kullanıcılarının bilgi ve tutumlarına dair yeterli veri bulunmamaktadır (Rogow ve Horowitz, 1995). Geri çekme yönteminin tercih edilmesinde, eğitim, cinsiyet, sosyo ekonomik- kültürel faktörlerin ve yönteme ilişkin tutumlarının etkili olduğu düşünülmektedir.

\section{Geri Çekme Yönteminin Cinsel Yaşama Etkileri}

Geri çekme yöntemi, aile planlaması açısından belli bir değer taşısa da, cinsel ilişkiye yönelik önemli olumsuzluklar içermektedir. Geri çekmenin tıbbi yan etkileri bulunmamakla birlikte, cinsel ilişkinin plato fazının yarıda kesilmesi, eşlerin cinsel doyumlarını azaltabilir. $\mathrm{Bu}$ yöntem, kadının çoğunlukla cinsel coşkunun doruk noktasında, orgazm olamamasına neden olabilmektedir (Yılmaz, 2003; Aile Planlaması ve Üreme Sağlığı, 2005; Bobak vd. 1997; Everett, 1998; Özyurda 2000).

Yapılan bazı çalışmalarda geri çekme yönteminin cinsel yaşama ilişkin olumsuz etkilerinden bahsedilmiştir (Berkiten ve Aslan, 2001; Yanıkkerem vd. 2006; Eryılmaz, 1999). Yanıkkerem'in çalışmasında, geri çekme yöntemini kullanan kadınların dörtte biri, cinsel yaşamlarını olumsuz etkilediği belirlenmiştir (Yanıkkerem vd. 2006), Bununla birlikte, Eryılmaz (Eryılmaz, 1999) ile Berkiten ve Aslan' in (Berkiten ve Aslan, 2001) yaptığı çalışmalarda da, geri çekme yöntemini kullanan erkeklerin cinsel açıdan tatmin olamadıkları belirlenmiştir.

Ayrıca geri çekme yöntemi birçok erkek tarafından kondom kullanımına tercih edilebilmektedir. Bazı erkekler için kondom kullanımı ereksiyon kaybı korkusu veya cinsel performansa ilişkin anksiyeteleri ortaya çıkarırken (Rogow ve Horowitz, 1995) geri çekmenin cinsel performans konusunda erkeğin kendi kontrolünde olması nedeniyle gururunu artırması göreceli olarak kabul edilebilirliğini artırmaktadır (Moore ve Rogow, 1994). Geri çekme erken boşalmaya eğilimli olan erkekler için daha az kabul edilebilmektedir (Rogow ve Horowitz, 1995). Geri çekme uzun süreli tek eşli ilişkilerde diğerlerine nazaran çok daha kabul edilebilir gözükmektedir (Lethbridge, 1990). Buda, çiftler arasında, cinsel iletişimin cinsel uyumun daha iyi olması ile ilişkili olabileceğini düşündürmektedir. 


\section{Geri Çekme Yönteminin Kullanımını Etkileyen Faktörler Sosyo Ekonomik Durum ve Eğitim}

Geri çekme yönteminin kullanımı sosyo-ekonomik durum ve eğitim gibi değişkenler tarafından etkilenip etkilenmediğine ilişkin yeterli veri bulunmamaktadır. Ramaswamy ve Smith'in çalışmasında (1976), İngiltere'de 1940-50 yılları arasında çiftlerin \%20-40'ı tarafından geri çekmenin kullanıldığını hatta bu sıklığın sosyoekonomik düzeyi düşük olanlar arasında \%60'a kadar yükseldiğini belirlemişlerdir (Ramaswamy ve Smith, 1976). Yapılan farklı çalışmalarda ise, geri çekme yönteminin sosyal ve ekonomik sınıf ayrımı olmaksızın çiftlerin dörtte biri tarafından kullanıldığı belirtilmektedir (Schneider ve Schneider 1991; Lethbridge, 1990).

Eğitim düzeyi bireylerin aile planlaması yöntem tercihini ve kullanımını etkilediğine ilişkin kesin bir veri bulunmamaktadır. Ancak yapılan çalışmalarda, geri çekme yönteminin eğitim düzeyi düşük çiftler tarafından yaygın olarak kullanıldığı belirlenmiştir (Bulut vd.1986; Novelli vd. 1980). Türkiye'de yapılan bir çalışmada ise, geri çekme yöntemini kullanan kadınların eğitim düzeyinin diğer aile planlaması yöntemlerini kullanan kadınlara göre, daha düşük olduğu saptanmıştır (Bulut vd.1986). Bununla birlikte literatürde, eğitim düzeyinin geri çekme yönteminin kullanımını etkilemediği de belirtilmektedir. (Anonim, 1996; Naomi vd. 1991). Ayrıca, eğitim düzeyinin geri çekme yönteminin etkin kullanımını etkileyip etkilemediğine iliş̧in yeterli veri bulunmamasının yanı sıra, yapılan bir çalışmada,eğitim düzeyi yüksek olan çiftlerin geri çekme yöntemini eğitim düzeyi düşük olan çiftlere göre daha etkin kullandıkları belirlenmiştir (Güngör vd. 2006).

\section{Cinsiyet}

Dünyanın birçok yerinde erkeklerin aile planlaması kullanımına olan destekleri veya engelleri ya da çiftlerin aile planlaması kullanımına karar verme biçimleri yöntem kullanımı etkileyen bir faktördür (Ergöçmen vd. 2004). Afrika'nın Botswana, Buruni, Gana, Kenya, Senegal, Sudan ve Togo'dan oluşan yedi ülkesinden elde edilen Nüfus ve Sağlık Araştırması verileri, aile planlaması yöntemi kullanımına eşiyle birlikte karar veren kadınların yöntem kullanım devamlılığı eşiyle birlikte karar vermeyen kadınlara göre daha yüksek olduğu belirlenmiştir (Özalp ve Tanır, 2001).

Güney Kore'de yapılan bir çalışma, eşleri tarafından aile planlaması kullanımı desteklenen kadınların aile planlaması kullanım 
sıklığı \%71 iken eşleri tarafından aile planlaması kullanımı desteklenmeyen kadınlar da bu sıklığın sadece \%23 olduğunu saptamıştır (Anonim, 1994). Türkiye'de yapılan çalışmalarda, eşinin ve ailesinin izin vermemesi nedeniyle hizmet almak için sağlık kuruluşlarına başvurmayanların sıklığı \%25 (Pasinlioğlu ve Taşkın, 1991) ve aile planlaması yöntemi kullanmayanların sıklığı ise \%14 (Türk vd. 2003) olarak belirlenmiştir. Bu durum ise bize aile planlaması yöntem tercihinde ve kullanımında kadınların eşlerinin desteklerinin önemli olduğunu göstermektedir.

Geri çekme yöntemi erkekler tarafından kullanılan bir yöntemdir. Santow, evlilik sürecinde erkeklerin karar verici otoriteye sahip olduklarına dair inancın, geri çekmenin kullanımı ile pozitif yönde bir ilişki olduğunu öne sürmüştür (Samtow, 1995). Bu yöntemin kullanımında erkeklerin kararlarının ve desteklerinin etkili olduğu düşünülmektedir.

\section{Din}

Geri çekme yönteminin kullanımını etkileyen birçok kültürel faktör bulunmaktadır (Ergöçmen vd. 1998). Bu faktörlerden birisi ise dini inanışlardır. Kültürel açıdan din insanların yaşamında önemli bir yere sahip (Anthony, 2000) olmakla birlikte din aile planlaması yöntemlerinin kullanımını belirleyen anahtar değişken olarak da tanımlanmaktadır (Öztürk vd. 2002; Musallam, 1983). İslam dininin kabul edilmesi ve $\mathrm{Hz}$. Muhammed döneminden günümüze kadar olan süreçte geri çekme yönteminin kullanımına ilişkin tartışmalar devam etmektedir (Rogow ve Horowitz, 1995; Omran, 1992). Ancak İslam âlimlerinin çoğunluğu, geri çekme (azil) yönteminin dinimizce yasak olmadığını, kadının rızasının olması durumunda uygun olduğunu belirtmişlerdir (Kılıcer, 2013). Müslüman ülkelerde, geri çekme yönteminin dinen uygun bir yöntem olduğunun düşünülmesi bu yöntemin daha fazla tercih edilmesini etkileyebilmektedir (Ergöçmen vd. 2004). Ancak, geri çekme yönteminin Hıristiyan ve Yahudi nüfusunun yoğun olduğu birçok ülkede de yaygın olarak kullanıldığı belirtilmektedir (Schneider ve Schneider, 1991). Bunun yanı sıra çoğunluğu Müslüman olan Türkiye'de yapılan çalışmalarda da geri çekmenin din bakımından uygun görüldüğü ve dini liderlerin bu yöntemi destekledikleri belirtilmiştir (Öztürk vd. 2002; Cebeci vd. 2004).

\section{Tutumlar}

Geri çekme yönteminin bazı kültürlerde, bir aile planlaması yöntemi olarak kabul edilmemesi (Potts, 1985), aile planlaması 
programları ve teşvik kampanyalarının sürekli olarak geleneksel yöntemlerin kullanımını göz ardı etmeleri (Rogow ve Horowitz, 1995) gibi tutumlar, birçok kadının kullandığı yöntemin geri çekme olduğunu bildirmek yerine yöntem kullanmadığını ifade etmelerine neden olmuştur. Bu durumun nedeni ise, aile planlaması uzmanlarının geri çekme yöntemini kullanan çiftlerin, modern aile planlaması yöntemlerine yönlendirilmesi ve de kullanması gerektiğine yönelik var olan tutum, davranış ve inançların geri çekme yöntemini kullanan çiftlere yönelik yapılan araştırmaları sınırladığı düşünülmektedir.

Modern yöntem kullandığını bildiren kadınların \%29'unun aslında geri çekme yöntemi kullandığı belirlenmiştir (Tsui vd. 1991). Geri çekme yöntemine yönelik var olan olumsuz tutumlar kullanım düzeyinin gerçekte olduğundan daha alt düzeyde belirlenmesine neden olmuştur (Rogow ve Horowitz, 1995; Tsui vd. 1991). Bu durumun nedeninin ise, sağlık personellerinin geri çekme yöntemini kullanan bireylere yönteme özel danışmanlık yapmadan sadece kullanılmaması gereken bir yöntem olarak vurgulanması ile ilişkili olabileceği düşünülmektedir.

Sonuç olarak; aile planlamasına ilişkin programların, kadın ve erkeklerin modern ve geleneksel yöntemler konusunda doğru bilgilenmesine odaklanması, söz konusu kişilerin olumlu davranış değişikliği göstermesine neden olabilir. Bu nedenle de hemşireler, aile planlaması hizmeti almak üzere aile planlaması hizmeti sunan sağlık kurum ve kuruluşlarına başvuran kişilerin gereksinimlerini ve yöntem tercihini etkileyen faktörleri belirlemelidir. Bu doğrultuda hemşireler aile planlaması yöntemleri hakkında bilgi vererek, çiftlerin durumlarına uygun aile planlaması yöntemini bilinçli olarak seçmelerine yardımcı olacaktır. Böylece çiftlerin seçtikleri aile planlaması yöntemini etkili ve güvenli bir şekilde kullanabilmeleri sağlanmış olacaktır. Geri çekme yöntemi en fazla kullanılan geleneksel aile planlaması yöntemi olması nedeniyle, çiftlere verilen aile planlaması danışmanlık hizmetleri kapsamı içerisine geri çekme yönteminin entegre edilmesi ve yöntemin etkin kullanımına yönelik eğitim ve danışmanlık hizmetlerinin verilmesi önerilmektedir. 


\section{KAYNAKLAR}

Anonim, (1997). Aile planlaması hizmetlerinde güncel bilgiler. s.83-86). Ankara: T.C Sağlık Bakanlığı Türk Eczacılar Birliği John Hopkins Üniversitesi Nüfus İletişim Servisi.(

Anonim, (2005). Aile planlaması ve üreme sağlığı. Ulusal Aile Planlaması Hizmet Rehberi T.C. Sağlık Bakanlığı Ana Çocuk Sağlığı ve Aile Planlaması Genel Müdürlüğü, Damla Matbaacılık, Ankara.

Anonim (2005). Doğal aile planlaması, içinde; Aile planlaması klinik uygulama el kitabı. (1996). İnsan Kaynağını Geliştirme Vakfı Yayınları, Sağlık Bakanlığı Ana Çocuk Sağlığı ve Aile Planlaması Genel Müdürlüğü Basım Evi, Ankara. Doğurganlık Bilinci ve Doğal Aile Planlaması, İçinde; Ulusal Aile Planlaması Hizmet Rehberi, kontraseptif yöntemler. (2005). Anadolu Matbaası, Ankara.

Anonim, 2009. Hacettepe Üniversitesi Nüfus Etütleri Enstitüsü (2009). Türkiye Nüfus ve Sağlık Araştırması (TNSA), (2008). Hacettepe Üniversitesi Nüfus Etütleri Enstitüsü, Sağlık Bakanlığı Ana Çocuk Sağlığı ve Aile Planlaması Genel Müdürlüğü, Başbakanlık Devlet Planlama Teşkilatı Müsteşarlığı ve TÜBiTAK, Ankara,Türkiye.

Akın, A. (1996), Aile Planlaması, temel kadın hastalıkları ve doğum bilgisi, (Edit: HA. Kişnişci), s. 165, Güneş Kitapevi, Ankara.

Anthony, G. (2000). Sosyoloji, (Çev: C. Güzel), Ayraç Yayınevi, Ankara.

Aytekin, N., Pala, K., Irgil, E., Aytekin, A. (2001). Family planning choices and some characteristics of coitus Interruptus users in Gemlik, Turkey. Women's Health Issues, 11 (5): 442-47.

Berkiten, A., Aslan, H. (2001). Kadınlarda aile planlaması yöntemlerinin cinsel yaşam üzerine etkileri [özet]. III. Ulusal Jinekoloji ve Obstetri Kongresi, 13-16, Eylül 2001. Ístanbul.

Bobak, M., Perry E., Lowdermilk, L. (1997). Maternity and women's health Care (Sixth Edition), pp.1173-1199, Mosby Company.

Bulut, A., Çilingiroğlu, N., Bertran, M. (1986). Is withdrawal a handicap for fertility regulation? Nufusbilim Dergisi, 8, 45-55.

Cebeci, SD., Erbaydar, T., Kalaca, S., Harmanci, H., Cali, S., Karavus, M. (2004). Resistance against contraception or medical contraceptive methods; a qualitative study on women and men in Istanbul. European Journal of Contraception and Reproductive Health Care, 9 (2), 94-101. 
Duben, A., Behar, C. (1996). İstanbul Haneleri: Evlilik, aile ve doğurganlık, İletişim Yayınları, İstanbul.

Elgood, C. (1970). Safavid medical practice. Luzac and Company Ltd., London.

Everett, S. (1998). Handbook of contraception and family planning. Bailliere Tindall, London.

Ergöçmen, B.A., İ. Koç, P. Senlet, Yiğit, E.K., Roman, E. (2004). A closer look at traditional contraceptive use in Turkey. The European Journal of Contraception and Reproductive Health Care, 9(4), 22124.

Ergöçmen, B.A., Koç, İ., Yiğit, E.K., Senlet, P., Roman, E. (1998). Gebeliği önleyici geleneksel bir yöntem üzerine analitik çalışma: Türkiye'de geri çekme yönteminin kullanımı.Türkiye Nüfus Ve Sağlık Araştırması (TNSA) ileri analiz çalışması.

Hacettepe Üniversitesi Nüfus Etütleri Enstitüsü, Orkide Basımevi, Ankara.

Eryılmaz, H. (1999). Kullandıkları kontraseptif yöntemlerin eşler üzerindeki etkileri ve kullanım hataları. Hemşirelik Forumu, Kadın Doğum Sayısı, 2 (3), 114-18.

Finger, WR. (1996). Withdrawal popular in some cultures. Contraceptive update. Network. 17 (1), 15-6, 24.

Goldberg, HI., Toros, A. (1994). The use of traditional methods of contraception among Turkish couples. Studies in Family Planning, 25 (2),122-8.

Güngör, S., Başer, İ., Göktolga, Ü., Eşber, Ö., Uğur, K. (2006). Koitus İnterruptus (geri çekme) yönteminin etkinliği ve eğitim seviyesinin önemi. Gülhane Tıp Dergisi, 48,8-10.

Güven S. Kontrasepsiyon, içinde; kadın hastalıkları ve doğum tanı ve tedavi (2004). (Ed:Günalp S, Tuncer S), Pelikan Yayıncılık, Ankara.

Hatcher, R.A., W. Rinehart, R., Blackburn, R., Geller, J.S., Shelton S.D. (1997). The essentials of contraceptive technology: A handbook for clinic staff. Johns Hopkins Population Information Program.

İnce, N., Özyıldırım, B.A. (2003). Gebelikten korunmada geri çekme yöntemi. Jinekoloji ve Obstetrik Dergisi, 17(3),180-82.

Kitapçıŏlu, G., Yanıkkerem, E. (2008). Manisa doğumevinde doğum yapan kadınların doğurganlık öyküleri, aile planlaması davranışı ve 
doğum sonrası aile planlaması danışmanlığı. Ege Tıp Dergisi, 47 (2), 87-92.

Kılıcer, ME., İslam'da aile planlaması.

http://dergiler.ankara.edu.tr/dergiler/37/769/9770.pdf Erişim Tarihi: 27 Şubat, 2013.

Kulu Glasgow, I., Hancıoğlu, A., Akadlı Ergöçmen, B. (1991). Contraceptive failure rates in Turkey. The Turkish Journal of Population Studies, 13, 3-13.

Lethbridge, D.J. (1990). The use of contraception by women of high socio-economic status. Health Care For Women Internatıonal, 11(3), 305-8.

Male Involvement in family planning. (1984). International Planned Parenthood Federation, 73-76, 79-80.

Moore KA, Rogow D (1994). Family planning and reproductive health: Briefing sheets for a gender analysis. Population Council, New York.

Musallam, B.F. (1983). Sex and society in Islam: Birth control before the Nineteenth Century. Cambridge University Press, Cambridge.

Naomi, R., Ayad, M., Ochoa, L.H., Wilkinson, M. (1991). Knowledge and use of contraception. Demographic and Health Surveys Comparative Studies, No.6. Columbia, Md: Institute for Resource Development/Macro Systems.

Novelli, G.G., Tocchella, F., Pinto, A. (1980). Study of the use of contraceptives by a town and a country population of Northern Italy. Acta Europaea Fertilitatis,11, 167-179.

Okun, BS. (1997). Family planning in the Jewish population of Israel: Correlates of withdrawal use. Studies in Family Planning, 28(3), 215-27.

Omran, A.R. (1992). Family planning in the legacy of Islam. Routledge, New York.

Oodit, G. (1996). Male contraception. Withdrawal: a time-honoured but risky method? Planned Parenthood Challenges, 2,25.

Özalp, S., Tanır, H.M. (2001). İstenmeyen gebelik ve düşüklerin kadın sağlığına etkileri. Aktüel Tıp Kadın Sağlığı Özel Sayısı, 6(1), 42-4. 
Öztürk, A., Güzel, H., Gün, I., Ostürk, Y. (2002). Opinions of imams about family planning and their use of methods in Kayseri, Turkey. European Journal of Contraception and Reproductive Health Care, 7(3), 144-9.

Özyurda, F. (2000). Ulusal Aile Planlaması Hizmet Rehberi, Aile Planlaması ve üreme sağığı, (3.Bs.) Damla Matbaacılık, Ankara.

Pasinlioğlu, T., Taşkın, L. (1991). Ebeveynlerin sağık ocaklarının verdiği ana çocuk sağlığı hizmetlerini kullanma durumları ve bunu etkileyen faktörler. Ege Üniversitesi Hemşirelik Yüksekokulu Dergisi, 7(3), 1012.

Potts, D.M. (1985). Coitus interruptus. In fertility control. (Edit:S.L. Corson, R.J. Derman, and L.B. Tyrer. Boston, MA), Brown and Company, Little. Ramaswamy, S., Smith, T. (Ed.). (1976). Practical contraception. Tunbridge wells, Pitman Medical, England.

Rogow, D., Horowitz, S. (1995). Withdrawal: A review of the literature and an agenda for research. Studies in Family Planning, 26(3),14053.

Samtow, G. (1993). Coitus interruptus and the twentieth century, Population and Development, 19, 767-92.

Samtow, G. (1995). Coitus interruptus and the control of natural fertility, Population Studies, 49(1), 19-43.

SexSmarts Surveys. (2002). Teens and sexual health communication. Henry J. Kaiser Foundation. http://www.kff.org/youthhivstds Erişim Tarihi: 2 Temmuz,2009,

Schneider, J., Schneider, P. (1991). Sex and respectability in an age of fertility decline: A sicilian case study. Social Science \& Medicine, 33(8), 885-95.

Taşkın, L. (2009) Doğum ve kadın sağığı hemşireliği. Sistem Ofset Matbaacilık, Ankara.

Tekiner, A.S., Çetin, F., Ceyhun, G., Kafkaslı, A. (2010). Planlanmamış gebelikler ile kontraseptif yöntemler arasındaki ilişki. Dirim Tıp Gazetesi, 85(2), 65-71.

Türk, R., Bakır, B., Karahan, E. (2003). Kars merkeze bağıı Azat, Gelirli, Karacaören köylerinde yaşayan kadınların sosyodemografik ve jinekolojik özelliklerinin 
kontraseptif kullanımına etkisi [özet]. IX. Ulusal Perinatoloji Kongresi: 26-30 Ekim, Ankara.

Tsui, A.O., S. Silva, VD., Marinshaw, R. (1991). Pregnancy avoidance and coital behavior. Demography, 28(1),1001-117.

Who makes reproductive decisions?" population reports. (1994). XXII,18-19. Withdrawal use in Pakistan. (1998). Population council, Pakistan: Islamabad.

World contraceptive use (2011). Erişim Tarihi: 17.Mart,.2012, http://www.un.org/esa/population/publications/contraceptive2011/wa Ilchart_front.pdf

Yanıkkerem, E., Acar, H., Elem, E., (2006). Withdrawal users perceptions of and experience with contraceptive methods in Manisa, Turkey. Midwifery, 22(3), 274, 84.

Yurdakul, M., Vural, G. (2001). Etki derecesi sınılı yöntem kullanma nedenleri ve hemşirenin aile planlaması hizmetlerindeki etkinliği. Sağlık ve Toplum, 11,42-5.

Yılmaz, A.C. (2003). Kullanılan kontraseptif yöntemlerin kadınlarda cinsellik üzerine etkisi. Bilim Uzmanlığı Tezi, Marmara Üniversitesi, İstanbul. 